\title{
Strikes as Forest Fires: Chicago and Paris in the Late Nineteenth Century ${ }^{1}$
}

\author{
Michael Biggs \\ University of Illinois at Urbana-Champaign
}

\begin{abstract}
Historians have persistently likened strike waves to wildfires, avalanches, and epidemics. These phenomena are characterized by a power-law distribution of event sizes. This kind of analysis is applied to outbreaks of class conflict in Chicago from 1881 to 1886. Events are defined as individual strikes or miniature strike waves; size is measured by the number of establishments or workers involved. In each case, events follow a power law spanning two or three orders of magnitude. A similar pattern is found for strikes in Paris from 1890 to 1899 . The "forest fire" model serves to illustrate the kind of process that can generate this distribution.
\end{abstract}

Transgressive contention occurs in waves. People suddenly shift from quiescence to defiance; they strike, sit in, demonstrate, or riot en masse; protest spreads across social networks and from place to place. When analyzed quantitatively, exogenous variables are unable to predict the magnitude of such waves. There is growing recognition of an endogenous process-a process of positive feedback (Biggs 2003). In short, people often engage in defiant collective action because others have recently done so, and not simply because their external circumstances have changed. This process has been investigated systematically in various ways. The thresh-

\footnotetext{
${ }^{1}$ Preliminary versions were presented to the American Sociological Association (thanks to funding from the British Academy and Nuffield College), to Nuffield College and to the Saïd Business School at the University of Oxford, and to the Center for Social Complexity at George Mason University. Ruth Aguilera, Robert Allen, David Barron, Tak Wing Chan, Susanne Choi, Claudio Cioffi-Revilla, John Dencker, Roberto Franzosi, Julian Go, John Goldthorpe, Anthony Heath, Stanley Lieberson, Fredrik Liljeros, Christian List, Claire Morton, Avner Offer, Maryjane Osa, Andrew Pickering, Felix Reed-Tsochas, Duncan Robertson, Donald Turcotte, and David Weakliem, and the $A J S$ reviewers all helped to sharpen the argument. Direct correspondence to Michael Biggs, Department of Sociology, University of Illinois at Urbana-Champaign, 326 Lincoln Hall, 702 South Wright Street, Urbana, Illinois 61801. E-mail: biggsm@uiuc.edu
}

(C) 2005 by The University of Chicago. All rights reserved. 0002-9602/2005/11006-0004\$10.00 
old model (Granovetter 1978) illustrates theoretically how a slight shift in individual proclivities can lead to a large jump in participation; the basic insight can be elaborated in more complex models. Event history analysis (Strang and Tuma 1993) estimates empirically whether the occurrence of one event raises the probability of another; the framework can incorporate an array of endogenous and exogenous variables.

This article contributes to our understanding of the dynamics of transgressive contention. It emphasizes that we can identify waves at very different scales. A wave on one scale-such as a peak in an annual time series-is composed of multiple waves on a smaller scale. In other words, waves are fractal. This conceptualization enables us to recognize a similar process of positive feedback operating at different scales. The mechanisms underlying such a process are elaborated here in terms of interdependence and inspiration. Positive feedback is implied by the metaphors employed by historically minded observers to describe the dynamics of large strike waves: metaphors of wildfire, avalanche, and epidemic. By taking these metaphors seriously, we can draw on recent research by natural scientists. Natural events like wildfires, landslides, and epidemics are characterized by a power-law distribution of event sizes. The probability of an (unfinished) event doubling in size is constant, no matter how large it has become already. This yields an empirical prediction for collective protest, which is tested here for the first time. The same kind of distribution is generated by the forest fire model. This simple model, like the threshold model, serves to illustrate an endogenous process of positive feedback.

Although academic interest in strikes has waned along with the intensity of class conflict in recent decades, no other kind of collective protest has been recorded in such detail. In the era before collective bargaining, when trade unions were small and fragile, strikes depended on the collective action of ordinary workers, leavened by the agitation of activists. This article focuses primarily on strikes in Chicago from 1881 to 1886, using exceptionally detailed data collected by the U.S. commissioner of labor. The period includes years of quiescence as well as a massive upsurge of class conflict in 1886. In the analysis, two levels of events are defined: individual strikes and miniature strike waves comprising strikes initiated on consecutive days. The size of these events is measured by either the number of establishments or of workers involved. For strikes and strike waves alike, I find that the size distribution follows a power law spanning two or three orders of magnitude. (An "order of magnitude" is the interval between one power of 10 and the next.) This analysis is extended to strikes in Paris from 1890 to 1899. Again, I find that the size distribution of strikes follows a power law spanning two orders of magnitude, though without additional clustering at the level of strike waves.

The findings vindicate the intuition of historical sociologists and social 


\section{American Journal of Sociology}

historians. They may not "prove" that these waves of collective protest were generated by an endogenous process of positive feedback, but they provide important new evidence. An alternative hypothesis- that the size of events merely reflects the distribution of firms in economic sectorscan be rejected. The method developed here can be applied to strikes in other contexts and to other forms of transgressive contention. If this finding is repeated, it should become a significant criterion for evaluating formal models of collective protest: they should generate "events" that also follow a power law. Finally, the results suggest how the contingency of particular events is compatible with the emergence, in aggregate, of stochastic regularity. A huge event still demands a particular historical explanation, but we need no longer treat it as an outlier.

The article begins by suggesting that a similar endogenous process of positive feedback operates at very different scales. It then elaborates the underlying mechanisms of interdependence and inspiration. Next, the power laws discovered for natural events are described. After introducing the data and method, results for Chicago in the 1880s are presented. The method is then extended to Paris in the 1890s. A simple model, the forest fire model, is discussed to illustrate the kind of process that can generate a power law. I address the broader implications of these findings in the conclusion.

\section{FRACTAL WAVES}

Transgressive contention occurs in waves: collective mobilization and collective protest are clustered in time and space (Koopmans 2004; Oberschall 1989; Oliver and Myers 2003). Waves are usually identified when actions are aggregated by national units and annual intervals. Thus Shorter and Tilly (1974, pp. 106-7) define a "strike wave" as a year when the number of striking workers and the frequency of strikes both exceed the average of the preceding five years by at least $50 \%$, all within the boundaries of a national state.

Nevertheless, we can recognize waves-clusters of transgressive contention - on a wide range of scales. Tarrow's (1998, chap. 9) "cycle of contention," which encompasses actions within different countries and may continue for some years, is a wave at the largest scale. Conversely, a single "incident" of protest-like a strike or riot-is simply a wave on the smallest scale. As Oliver and Myers observe, there are "smaller waves within waves, and waves within those waves" (2003, p. 7). This invites the appellation fractal, which simply denotes self-similarity or self-affinity at different scales (Mandelbrot 1983). Just as Abbott (2001) uses the con- 


\section{Strikes as Forest Fires}

cept to probe social and cultural structures, we may use it to sharpen our conceptualization of the dynamics of transgressive contention.

Consider Shorter and Tilly's (1974) definition of a strike wave. For the United States, 1886 meets their criteria. But the year's strikes were concentrated in May; that single month accounted for half the total number of workers involved in strikes throughout the year (Bradstreet's, January 8,1887 , p. 21). Applying the same numerical threshold-50\% higher than the average of the last five intervals - at this finer scale of months, there would be a strike wave in May 1886. To disaggregate further, on the scale of days, there would be a strike wave on May 1. Conversely, the same threshold could be applied on a coarser scale. The proportion of workers who struck in 1919 dwarfs any other year (before or since), but the surrounding years were also high. There would be a strike wave in the quinquennia 1916-20. Nothing compels us to restrict "waves"-in Shorter and Tilly's (1974) operational definition as peaks in a time series-to annual intervals (or indeed to national societies). ${ }^{2}$

Whatever the scale, waves of contention are puzzling insofar as they resist explanation in terms of exogenous variables (cf. Abbott 1988). If causes such as relative deprivation or political opportunities could "predict" the timing and magnitude of waves, then we would have a straightforward and satisfactory explanation. This sort of explanation has been tested most rigorously for strikes. After all, national states have been collecting comprehensive data on strikes since the late 19th century, providing time series over a lengthy period. Social scientists have attempted, with increasing statistical sophistication, to correlate strikes-measured by strike frequency or the number of striking workers-with various exogenous variables. This literature has focused on adjudicating between competing causes, most notably between economic and political ones (for the United States, see Snyder [1975, 1977], Edwards [1981, chap. 3], Kaufman [1982], Skeels [1982], and McCammon [1993]). Certainly some variables emerge as statistically significant; we usually find a negative relationship with unemployment. Nevertheless, it is still not possible to predict peaks in the series, when class conflict suddenly erupted. Analysis of strikes in the United States before the New Deal does not explain the great upsurges in 1919 and 1886; indeed, the latter is predicted to be an "average" year (Biggs 2003). Even Franzosi's (1995) analysis of Italian strikes in the postwar period, the most sophisticated of the genre, does not predict the autunno caldo ("hot autumn") of 1969.

These limitations allow us to understand why the eruption of transgressive contention has taken social scientists by surprise, most memorably

${ }^{2}$ This may recall a very different example, of physicians allocating tonsillectomies (Abbott 2001, p. 194). 
American Journal of Sociology

in 1989 (Koopmans 2004). It is comforting that participants and opponents were equally unable to predict the upsurge. After the fall of the Berlin Wall, with the benefit of hindsight, three-quarters of East Germans still admitted to being totally surprised by what had happened (Kuran 1991, p. 121). In response, we could simply admit defeat; if each wave of contention results from a unique conjunction of circumstances, the subject may be excluded from the domain of (generalizing) social science. A more ambitious response is to pursue a different kind of explanatory strategy, which emphasizes an endogenous process of positive feedback (Biggs 2003). This kind of self-reinforcing process "feeds on itself to the point where there is a continual increase or decrease of some variable, and there is no true point of equilibrium" (Boulding 1968, p. 103).

Positive feedback is inherent in the character of defiant collective action, because an individual's decision to participate is strongly influenced by the action of others. Workers surely look to the recent actions of other workers, and not just at their external economic and political circumstances; strikes can lead to further strikes, unionization to more unionization. This fundamental insight has appeared in various guises in different sociological literatures. As "circular reaction," it was present in Blumer's (1951) synthesis of collective behavior. This incarnation had the unfortunate effect of associating positive feedback with irrationality. Just as sociologists were rejecting the tradition of collective behavior, positive feedback emerged in formal models of collective action, originating with Granovetter's (1978) threshold model (see Oliver 1993). Ironically, the insight is now most often appreciated within the tradition of rational choice, broadly defined (e.g., Chong 1991; Hedström 1998; Kuran 1995; Oberschall 1989).

\section{MECHANISMS OF INTERDEPENDENCE AND INSPIRATION}

Before proceeding to empirical analysis, it is worth outlining theoretical "mechanisms" (Elster 1989) that give rise to positive feedback. For transgressive contention, we can identify two core sets of mechanisms; I term these interdependence and inspiration. In elaborating these mechanisms, my aim is to show why people have reason to participate in collective action because others have recently participated. The emphasis is on the logic of individual decision making. After all, causal explanation requires understanding the reasons for action, as Weber famously observed. Moreover, sociologists still tend to associate positive feedback with the irrationality of collective behavior, and therefore it is important to emphasize how positive feedback can be generated by rational decisions. "By assuming that actors act intentionally," as Hedström (1998, p. 311; original 


\section{Strikes as Forest Fires}

emphasis) suggests, "we are forced to probe more deeply into the reasons or mechanisms that explain why actors follow the lead of others." The discussion will focus on strikes for illustration.

Interdependence is inherent in collective protest (Chong 1991, chap. 6). For the great majority, a decision to participate in protest is contingent on the actions of others (Schelling 1978, p. 17). At the very least, one worker alone cannot "strike"; he or she would be fired. The motivation to participate increases with the number (or proportion) of participants, for three reasons. First, the expected collective benefits increase. The greater the number of workers on strike, the more reason they have to hope for concessions. Second, the expected individual and collective costs decrease. The greater the number of workers on strike, the less reason they have to fear being replaced or singled out for victimization. Neither reason would dissuade truly selfish individuals from trying to free ride, of course (Olson 1971). Another reason may prove persuasive. As the number of participants increases, so does the the moral obligation to participate, and the likelihood of being punished for violating this obligation. The greater the number of workers on strike, the more reason a potential "scab" would fear ostracism or violence.

Interdependence applies to collective protest where everyone either succeeds or fails—or, at least, success for some will make success for others more likely. Interdependence explains propagation within a collectivity or group and thus predominates at smaller scales. The second set of mechanisms operates between such groups and thus predominates at larger scales. Inspiration is less familiar, as theories of collective action have focused on a single group pursuing an indivisible collective goal. Even in the absence of interdependence, collective action by one group can nonetheless inspire another group to act.

Because collective protest is rare and risky, the actions of others are potentially inspirational for three reasons. People are not continually deciding whether to initiate transgressive contention. Learning that others elsewhere have acted raises the possibility-and so provides what Oliver (1989, p. 11) calls "an occasion for deciding" one way or the other. Hearing that other workers have struck, workers are more likely to consider whether to strike. In addition, the action of others can influence a group's expectations of their own success. Before the outcome of others' action is clear, the simple fact that they have acted implies that they expect success. That inference provides a second-order reason to hope-one based on "expected" facts rather than "accomplished" facts (borrowing terminology from Pigou [1929, p. 73]). Inferring that other workers hope to win a strike, workers may raise their own expectations of victory. Once the outcome of others' action becomes clear, more information is provided. 


\section{American Journal of Sociology}

If they are successful, there is further reason to hope for success. Conversely, of course, failure should lower expectations. ${ }^{3}$

Interdependence and inspiration provide reasons for people to act because others have done so. These two sets of mechanisms can be differentiated as ideal types; in reality, they are often intertwined. Moreover, they depend on culturally constructed-and contested-answers to the questions, "Who are we?" and "Are they like us?" Interdependence implies solidarity; inspiration depends on the "attribution of similarity" (McAdam, Tarrow, and Tilly 2001). These complexities are important. The point here is to demonstrate the theoretical plausibility of positive feedback.

\section{POWER LAWS}

There are two principal sources of empirical evidence for positive feedback. First, investigations of significant waves of contention show that exogenous changes are not sufficient to explain the magnitude of the upsurge and provide qualitative evidence that people were influenced by others' actions. Such episodes include the sit-ins against racial segregation in the U.S. South in 1960 (Oberschall 1989), the Iranian Revolution of 1979 (Kurzman 1996), and the fall of Communism in Eastern Europe in 1989 (Koopmans 2004; Kuran 1995, chap. 16). Second, event history analyses of collective protest estimate to what extent the occurrence of one event makes it more likely that another will occur, usually within an interval of days or weeks (e.g., Andrews and Biggs 2002; Conell and Cohn 1995; Myers 1997, 2000; Soule 1997). ${ }^{4}$

A new method of empirical analysis can be derived from the metaphors used to describe waves of contention. Metaphors of wildfire, epidemic, and avalanche are ubiquitous. When American workers organized and struck en masse in 1886, Engels (1887, p. $i$ ) described how the movement "spread with the rapidity of a prairie fire." "The fever of joining [the Knights of Labor] seemed to be epidemic," recalled one railroad worker (quoted in Allen 1942, p. 26). Metal manufacturers in Chicago noted that "in the majority of our factories content existed before this contagious fever caught them" (Chicago Tribune, May 9, 1886, p. 9). Many social historians and historical sociologists employ the same metaphors. Hobs-

\footnotetext{
${ }^{3}$ Remarkably, Conell and Cohn (1995) find that even defeat raises the probability that other workers will strike. This finding may be interpreted as showing the importance of the first reason for inspiration: the opportunity to make a decision.

${ }^{4}$ Event history analyses of organizational founding (e.g., Conell 1988; Conell and Voss 1990; Hedström 1994; Hedström, Sandell, and Stern 2000; Voss 1988, 1993) provide similar findings-one founding raises the probability of another-though the time interval is annual.
} 
bawm (1985, p. 18) discerns a "snowball effect" in the mobilization of British workers in 1889-90. According to Perrot ([1984] 1987, p. 17), strikes "spread like an epidemic" in France in May 1880 and May 1890. Moore (1978, p. 244) refers to a strike by German coalminers in 1889 as "a spark which ignited a 'prairie fire' in the Ruhr." Aside from strikes, other forms of protest attract the same metaphors (e.g., Polletta 1998). Why not take these metaphors seriously?

Wildfires and landslides_-along with earthquakes_-have recently been investigated by geologists and physicists (Malamud and Turcotte 1999; Turcotte 1997; Turcotte et al. 2002). Remarkably, these disparate phenomena share the same kind of cumulative distribution of event sizes. The number $(N)$ of events exceeding a certain size $(x)$, follows a power law:

$$
\begin{gathered}
N(\operatorname{size}>x)=c x^{-\beta}, \\
\ln N(\operatorname{size}>x)=\ln c-\beta \ln x .
\end{gathered}
$$

If the cumulative distribution follows a power law, then so does the density distribution:

$$
\operatorname{prob}(\operatorname{size}=x)=c^{\prime} x^{-\alpha}
$$

where $\alpha=\beta+1$. I will focus on the cumulative distribution, because it facilitates interpretation and estimation. As a matter of terminology, the word "law" is unfortunate, because that is best reserved for relationships between two or more variables. Calling the power law a Pareto distribution invites confusion because that also denotes two related types of distribution (power law is synonymous with a Pareto distribution of the first kind).

A power law entails a skewed distribution, with many more small events than large ones. The greater the magnitude of $\beta$ (the steeper the slope), the more pronounced the skew: the greater the preponderance of small events relative to large ones. The distribution is also "fat tailed," which implies many more huge events than would "normally" be expected from more familiar distributions like the lognormal. If $N$ events exceed size $x$, then $2^{-\beta} N$ events exceed $2 x$. The distribution has some strange properties. If $\beta \leq 2$, then the distribution has no variance; if $\beta \leq 1$, it has no mean. Although these statistics can be computed for a given sample, they will not converge on a finite nonzero value as the sample size increases.

To make all this more tangible, consider the example of wildfires in the Australian Capital Territory over several decades (Turcotte 1997, fig. 
American Journal of Sociology

16.17, p. 338). The cumulative distribution of size, measured by area burned, follows a power law with $\beta=.59$. Observing a fire in progress, the probability of it doubling in size is $.66\left(=2^{-\beta}\right)$-regardless of how large it is already. This means that the larger a fire becomes, the more likely it will spread further. If a fire has consumed only $1 \mathrm{~km}^{2}$, the probability of it burning at least $2 \mathrm{~km}^{2}$ is .66 ; once it has consumed $10 \mathrm{~km}^{2}$, the probability of it burning at least $11 \mathrm{~km}^{2}$ is .95 ; once it has consumed $100 \mathrm{~km}^{2}$, the probability of it burning at least $101 \mathrm{~km}^{2}$ is .99 . Positive feedback is commonly misconceived as implying the inevitability of explosive growth. This fallacy is easily dispelled. Most fires are small: the median $\left(.5^{-1 / \beta}\right)$ burns about $3 \mathrm{~km}^{2}$. Mathematically, a power law has no limits, either at the upper or lower end of the scale. In reality, of course, wildfires fall within a certain size range. In this sample, the power law spans the range from $.1 \mathrm{~km}^{2}$ to $1,000 \mathrm{~km}^{2}$.

For wildfires in general, estimates of $\beta$ range from .3 to .6, spanning up to six orders of magnitude. For landslides (also measured by area), whether caused by earthquakes or rainfall, estimates of $\beta$ range from 1.3 to 2, spanning three orders of magnitude (Malamud and Turcotte 1999; Pelletier et al. 1997; Turcotte et al. 2002). The same distribution can be created experimentally with avalanches in piles of rice, though this depends on the type of rice (Frette et al. 1996). As for epidemics, a study of measles epidemics in island populations finds that the number of infected cases follows a power law with $\beta=.3$, spanning three orders of magnitude (Rhodes and Anderson 1996).

Surely it would surprise historically minded observers to learn that the vehicles of their metaphors share such a quantitative resemblance. This leads us to a bold hypothesis: that waves of transgressive contention have the same kind of size distribution. This hypothesis would vindicate the intuition of historians and provide further evidence for positive feedback. Do strike waves follow such a power law? Strike waves are clusters of strikes; the notion of fractals enables us to recognize individual strikes as waves on a smaller scale. Do strikes also follow a power law?

This would not be unprecedented in social science. Power laws were first discovered for social phenomena (Cioffi-Revilla manuscript). In 1896, Pareto claimed that the distribution of personal income is governed by a power law (Persky 1992), though we know now that it applies only to the upper reaches of the distribution (Champernowne and Cowell 1998). The fact that the distribution of city population follows a power law with $\beta=1$ was discovered in 1913. This special case of a power law with $\beta=1$ has come to be known as "Zipf's law," after its most enthusiastic proponent (Zipf 1949). ${ }^{5}$ This power law holds for cities in many times

${ }^{5}$ Zipf's law is usually expressed by relating the size of the $i$ th entity $\left(S_{i}\right)$ to its rank 
and places (Fujita, Krugman, and Venables 1999, chap. 12). The same power law describes the size of firms (Axtell 2001). In addition, power laws have been found to describe (absolute) growth rates, such as the daily rate of return in financial markets (Mandelbrot 1963) and the growth of formal organizations (Liljeros 2001). All these phenomena differ from events like fires or strikes, where the distribution summarizes the completed size of events, each of brief duration, over a lengthy period. Wars are events of this character. Richardson (1948) showed that the cumulative distribution of wars over the period 1820-1945-measured by deathsfollowed a power law, with $\beta=.5$ over five orders of magnitude (see also Roberts and Turcotte 1998; Cederman 2003).

\section{DATA AND METHOD}

The method used here, following the lead of natural scientists, is simple. It entails delimiting clusters of collective protest - events-and examining the resulting cumulative size distribution. This procedure disregards when events occur in time. ${ }^{6}$ It is concerned with the process that generates events. The meaning of "event" in this analysis differs from its meaning in more familiar methods, like event history models of diffusion (Strang and Tuma 1993), narrative analysis of event structures (Griffin 1993), or optimal matching of event sequences (Abbott and Hrycak 1990). These methods analyze relations between events; either events are correlated with one another in order to make inferences about causation, or sequences of events are matched in order to discern typical patterns. Here, by contrast, we focus on the size of events, in order to make inferences about the underlying generative process. Therefore this analysis of strike waves is roughly equivalent to event history analysis of individual strikes (e.g., Conell and Cohn 1995), insofar as both attempt to capture how collective action propagates from one group of workers to another. This method is distinctive in two ways. First, it tests a bold conjecture, derived from

in the distribution $\left(r_{i}\right): S_{i}=c r_{i}^{-1}$. Of course, $r_{i}=N$ (size $\geq S_{i}$ ), in the absence of tied ranks.

${ }^{6}$ Thus it differs from time-series analysis, such as a simple autoregressive equation:

$$
Y_{t}=a+\phi Y_{t-1}+\epsilon
$$

Even if $t$ refers to daily intervals, this method cannot be used to analyze how a strike propagates across firms, because that occurs within a single day. It could be used to investigate the duration of strike waves, as defined here. For Chicago between 1881 and 1886, when $Y_{t}$ is a dichotomous variable coded one if a strike was initiated on day $t$, a positive effect emerges from the equivalent logistic regression: $\operatorname{prob}\left(Y_{t}=\right.$ $\left.1 \mid Y_{t-1}=1\right)$ is more than double $\operatorname{prob}\left(Y_{t}=1 \mid Y_{t-1}=0\right)$. This finding is convergent with the results of my analysis of strike waves. 
historical metaphors: that the size distribution of events conforms to a power law. Second, it is allied with formal models of process which generate events of this kind, to be discussed below.

The U.S. Bureau of Labor Statistics published exceptionally detailed data on strikes and lockouts in the late 19th century. The commissioner of labor's third annual report published details of every strike and lockout from 1881 to 1886. (Henceforth, lockouts are subsumed under "strikes.") The bureau's staff compiled a list of strikes by searching through newspapers and periodicals and by canvassing employers and labor organizations in each district. They then obtained details from both sides to each dispute, yielding 35 fields of information in the published report (U.S. Commissioner of Labor 1887, pp. 9-10). Subsequently, the tenth annual report continued coverage-albeit with less detail— to the middle of 1894. Later reports published only summary figures.

Disaggregated data from this source have recently been exploited by economic historians and labor economists (Card and Olson 1995; Currie and Ferrie 2000; Rosenbloom 1998), following Friedman's (1988, 1998) pioneering work. They concentrate on what happened after a strike had begun: how long it lasted, and whether workers were victorious (see Biggs 2002). By contrast, here the analysis is restricted to the initiation of strikes and strike waves: how many workers or firms were involved.

The scope is one city, Chicago, in the years from 1881 to 1886 (U.S. Commissioner of Labor 1887, table 1, pp. 100-171, and table 2, pp. 62426). Because the bureau's method of classification changed in the subsequent report, extending the series to 1894 would pose problems of consistency. The bureau tabulated strikes by locality. Only in a few cases, like the national telegraphers' strike of 1883 , did it combine the actions of workers in different places. ${ }^{7}$ This tabulation reflected the locus of class conflict in the late 19th century. Apart from railroads, almost all employers were confined to one location. Many local trade unions were independent (Friedman 1999), while those affiliated with international unions still had a large measure of autonomy. The Knights of Labor, the leading workers' organization at this time, was also decentralized; most of its local assemblies were combined into geographical district assemblies.

As a laboratory of class conflict, Chicago is an obvious choice. During the 1880s it overtook Philadelphia to become the United States' secondlargest metropolis. In the first half of the decade, workers were quiescent; strikes were few and far between. Class conflict erupted at the beginning of May 1886, when 70,000 workers went out on strike for shorter working hours and higher wages; more workers in Chicago than in any other city

\footnotetext{
${ }^{7}$ This strike is necessarily excluded from the analysis below, as the bureau did not report separate figures for Chicago.
} 
took part in the strikes. Police clashed with anarchists in the notorious Haymarket incident. By the end of May, most workers had accepted defeat. In the fall, however, packinghouse workers attempted to defend their gains in two successive strikes (Biggs 2002).

There are no shifts in external circumstances sufficient to explain the upsurge of transgressive contention in 1886 (Biggs 2003). At the national level, political and economic variables-in a time-series analysis over the period 1881-1936 - predict an average year for strikes. Although the economy was emerging from recession by 1886, unemployment was still high. In Chicago, political opportunities were shrinking. The mayor had signaled a shift toward repressive policing by promoting an inspector who brutally suppressed picketing (Schneirov 1998, chap. 7). A peculiar feature of the upsurge of 1886 was the synchronization of strikes for May 1. In the fall of 1884, two dozen trade unionists, styling themselves the Federation of Organized Trades and Labor Unions, had resolved "that eight hours shall constitute a legal day's labor from and after May 1, 1886" (1884, p. 14). But they had neither resources nor authority, and the plan was disavowed by the paramount leaders of the Knights of Labor. A small number of working-class activists embraced the campaign. Even they were taken by surprise as ordinary workers mobilized en masse-in Chicago and other major cities-in the spring of 1886. I argue that this rapid mobilization can be explained by an endogenous process of positive feedback (Biggs 2003). As each new group of workers became sufficiently optimistic to organize, the fact of their organization inspired others to follow suit. New hopes gave rise to new organization; new organization became evidence that such hopes were justified.

The analysis conducted here encompasses not only the massive upsurge of May 1886, but also the sporadic activity of "normal" times. It aggregates workers' actions into two levels of event—strikes and strike waves-one nested within the other.

Individual strikes are relatively easy to delineate, almost like landslides or wildfires. The commissioner decided "to make the establishment the unit in the tabular presentation, and not the strike" (1887, p. 11). Where strikes involved multiple establishments, the information was tabulated on multiple records-unless it was identical, in which case there was one record with total figures. This testifies to the meticulous detail gathered by the bureau. There were 533 records for locations in Cook County (which includes industrial districts just outside the city's jurisdiction). In many cases, multiple records referred to incidents involving workers in the same occupation, industry, and location, who struck on the same day. These differed in other particulars, such as the day on which strikers eventually returned to work or the exact nature of their demands. Because such differences are irrelevant for analyzing the initiation of strikes, these 


\section{American Journal of Sociology}

multiple records are combined, creating 341 strikes. ${ }^{8}$ Each of these events was a dense cluster of interdependent actions by a particular group of workers, which occurred on a single day.

To capture clusters of action involving different groups of workersconnected by inspiration-strikes must be aggregated into strike waves. Such events are not neatly bounded, but neither are epidemics. To analyze measles epidemics, Rhodes and Anderson (1996) define events by aggregating cases in consecutive months in which one or more new cases of infection appeared on an island. In a similar fashion, I create strike waves by aggregating strikes that began on consecutive days in which one or more new strikes were initiated within the city. Strike waves are thus delimited by days without new strikes, just as measles epidemics are delimited by months without new cases. This operationalization of "strike wave" differs fundamentally from Shorter and Tilly's (1974), which identifies intervals of time with unusually high levels of strikes. My definition, by contrast, delimits clusters of strikes, with great variance in size. Of 163 strike waves, four-fifths consist of a single strike. The largest-at the beginning of May 1886 - combines 115 strikes, which together contributed over $60 \%$ of the strikers for the whole year. (This wave does not, however, include the largest single strike, by carpenters in 1883.)

It should be emphasized that this definition of strike wave captures the outbreak of strikes within a short span of time. The largest wave combines strikes initiated over nine consecutive days (almost all of which occurred over three days); two other waves combine strikes initiated over four days; the remainder lasted for three days at the most. By comparison, the mean duration of strikes in this period was 14 days, and the median seven days (cf. Biggs 2002). A strike wave usually reached its full extent before its constituent strikes had ended in victory for one side or the other, with very few exceptions. This justifies my relatively parsimonious definition of wave. A more generous definition-encompassing all strikes separated by intervals of seven days or less, for example-would include some strikes that had terminated before other strikes had even begun.

For both levels of event-strikes and strike waves-there are two measures of size: the number of firms (strictly speaking, establishments) and the number of workers involved. The correlation of these logged measures is modest ( $r=.55$ and .59 for strikes and waves respectively). However size is measured, it cannot be zero. Mathematically, a power law excludes zero. Substantively, nonevents are literally uncountable. It is inconceivable

\footnotetext{
${ }^{8}$ Two corrections are made: the strike of lumber shovers (no. 964) began on May 1, not May 10; a lockout of packinghouse employees (no. 57) on May 24 is not mentioned in any newspaper, and so it is excluded.
} 


\section{Strikes as Forest Fires}

to ask how many strikes involved zero workers, for example, because that means asking how many strikes did not occur.

To test whether the size of events follows a power law, a linear equation is estimated: ${ }^{9}$

$$
\ln N(\operatorname{size} \geq x)=\ln c-\beta \ln x .
$$

The cumulative is preferred to the density distribution (which would mean estimating $\alpha$ ) as it obviates the need to choose arbitrary size intervals. By

plotting every data point, rather than aggregating them into a handful of bins, we view the data in all their messy glory. Scientists investigating power laws in nature indicate goodness of fit with $R^{2}$. This value is inevitably high, because a cumulative distribution always slopes downward; a good fit is indicated only by extremely high values. The appendix describes estimation of the standard error for $\beta$ and of prediction intervals for the power law.

\section{RESULTS}

Table 1 summarizes the results for Chicago between 1881 and 1886 . Figure 1 shows the cumulative distribution of firms involved in strikes. The data are compared to the best-fitting power law, a straight line on the logarithmic graph, with $\beta=.92\left(R^{2}=.98\right)$. The estimated $95 \%$ prediction interval is also indicated: if we draw samples of 341 events from a distribution defined by this power law, $95 \%$ of these points fall within that interval. The prediction interval highlights some discrepancies. There are significantly fewer strikes than predicted involving two to four firms. In effect this discrepancy shows that it was relatively difficult for a strike to spread beyond a single firm. Strikes that achieved a "critical mass" of five firms, however, conform more closely to the power law. There is still some systematic deviation, with more strikes than expected involving 1020 firms. Most important, however, the power law predicts the occurrence of the very largest strikes, involving over 100 firms. This is rather remarkable, especially as compared to an obvious alternative skew distribution: the lognormal, also described by two parameters. That alternative fits very poorly $\left(R^{2}=.87\right)$ and makes the largest strikes appear as abnormal outliers.

Figure 2 shows the cumulative distribution of workers involved in strikes. The power law fits remarkably well, with $\beta=1.0\left(R^{2}=.99\right)$, but only for strikes involving 150 or more workers. This threshold is roughly

${ }^{9}$ Where the measure of size is discrete (as with strikes) rather than continuous (e.g., wildfires), it makes sense to consider $N($ size $\geq x)$ rather than $N($ size $>x)$. 
American Journal of Sociology

TABLE 1

Size Distribution of Events: Strikes in Chicago, 1881-86

\begin{tabular}{clccccc}
\hline \hline Event & Measure & Range & Threshold & $\beta$ & SE & $R^{2}$ \\
\hline Strikes $(n=341) \ldots \ldots \ldots \ldots$ & Firms & $1-301$ & & .92 & .06 & .98 \\
Strike waves $(n=163) \ldots$ & Workers & $3-12,000$ & 150 & 1.00 & .08 & .99 \\
& Firms & $1-714$ & & .75 & .06 & .99 \\
& Workers & $3-68,807$ & 150 & .88 & .13 & .97 \\
\hline
\end{tabular}

equal to the median size, and so the power law fits the upper half of the distribution; it still spans almost two orders of magnitude. The lower half of the distribution is flatter: there are fewer small events than the power law would predict. Incidentally, this flattening at smaller scales is also characteristic of landslides (Pelletier et al. 1997).

For strikes, the explanation for the flattening of the distribution at smaller scales has two parts. First, when a firm was struck, almost all its employees would join the strike. In over four-fifths of strikes, the entire workforce was involved. Exceptions occurred mainly where one section of workers in a large establishment (skilled butchers in a meat-packing plant, for example) struck for their own benefit. To some extent, the high rate of participation may be due to the inherent difficulty of distinguishing workers who actually decided to strike from those thrown out of work if the firm was forced to suspend operations. ${ }^{10}$ The high rate of participation surely also demonstrates the strength of interdependence among workers within the same establishment. On one hand, proponents of a strike would initiate collective action only when they were sure of a positive response from the workforce as a whole; on the other, once collective action had been initiated, all employees had compelling reasons to join.

Therefore the number of workers involved in a strike was essentially the product of the number of firms involved and the number of employees per struck firm. The mean of the latter (averaging across strikes) was 162, and the median was 65 . As these figures show, workers in small establishments tended not to strike (Biggs 2002). This provides the second part of the explanation for why the distribution becomes flatter at smaller scales. Altogether, workers in larger firms were most likely to strike, and when they went on strike, the entire workforce would come out. Thus relatively few strikes involved a handful of workers. Clearly it is the propagation of a strike among firms that gives rise to a power lawmeasured directly by the number of firms involved and indirectly by the number of workers involved.

${ }^{10}$ The figures used here do include the number of workers "indirectly involved," as well as the number of strikers, but in most cases the former was zero. 
Strikes as Forest Fires

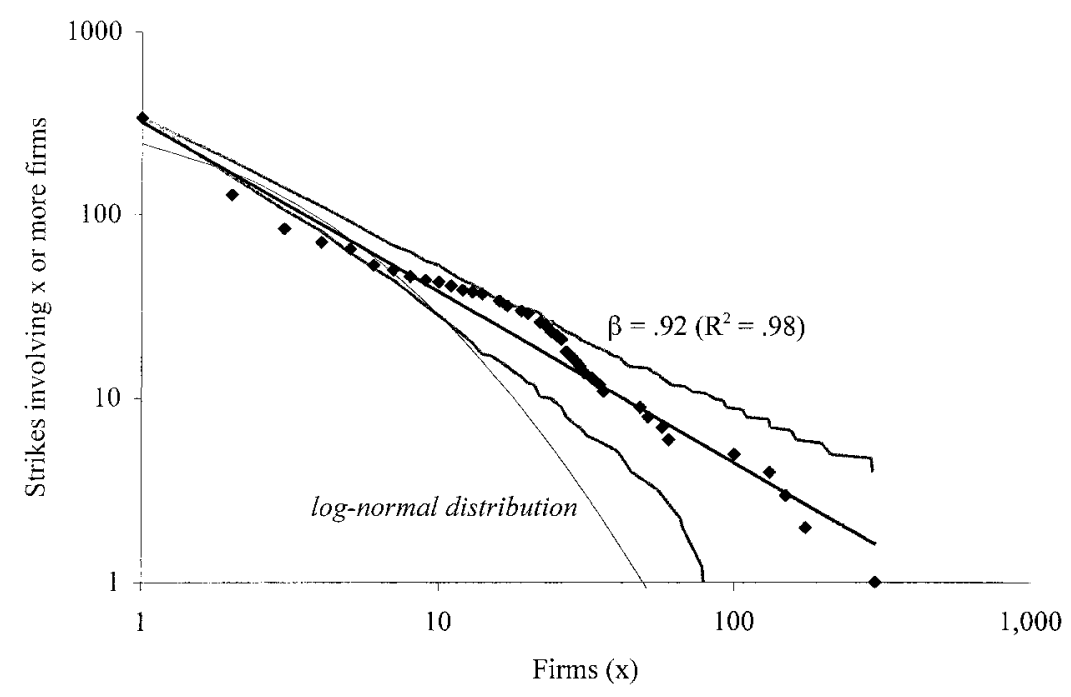

Fig. 1.-Firms involved in strikes, Chicago, 1881-86

Strike waves show a remarkably similar pattern to strikes. Figure 3 shows the cumulative distribution of firms involved in strike waves. The power law, with $\beta=.75$, is actually a better fit $\left(R^{2}=.99\right)$ than for strikes and spans nearly three orders of magnitude. Discrepancies include the disproportionate number involving around 30 firms and a long gap until the six largest waves-which occurred in May 1883, May 1884, and May 1886. These nevertheless fall within the $95 \%$ prediction interval, which is wider than for figure 1. Most important, the huge wave in early May 1886 fits perfectly into the distribution. The cumulative distribution of workers involved in strike waves (not shown) is also similar to that for strikes. A power law with $\beta=.88$ is a good fit $\left(R^{2}=.97\right)$, again above about 150 workers. The distribution implies a return time of about 12 years for an event comparable to the massive strike wave that occurred at the beginning of May $1886 .{ }^{11}$ In both cases, $\beta$ is smaller for strike waves than for strikes, indicating a greater preponderance of larger events relative to smaller ones.

To interpret these results, we can return to the process of growth that is implied by a power law. Once an (unfinished) event has grown to a given size, the probability that it will grow to at least double that size is $2^{-\beta}$. If we see a strike in progress, the probability that it will grow to involve twice as many firms-in the same industry or occupation, in the

${ }^{11}$ The return time is the average time between events which attain a given size, over a lengthy period. It does not imply that such events are cyclical. 
American Journal of Sociology

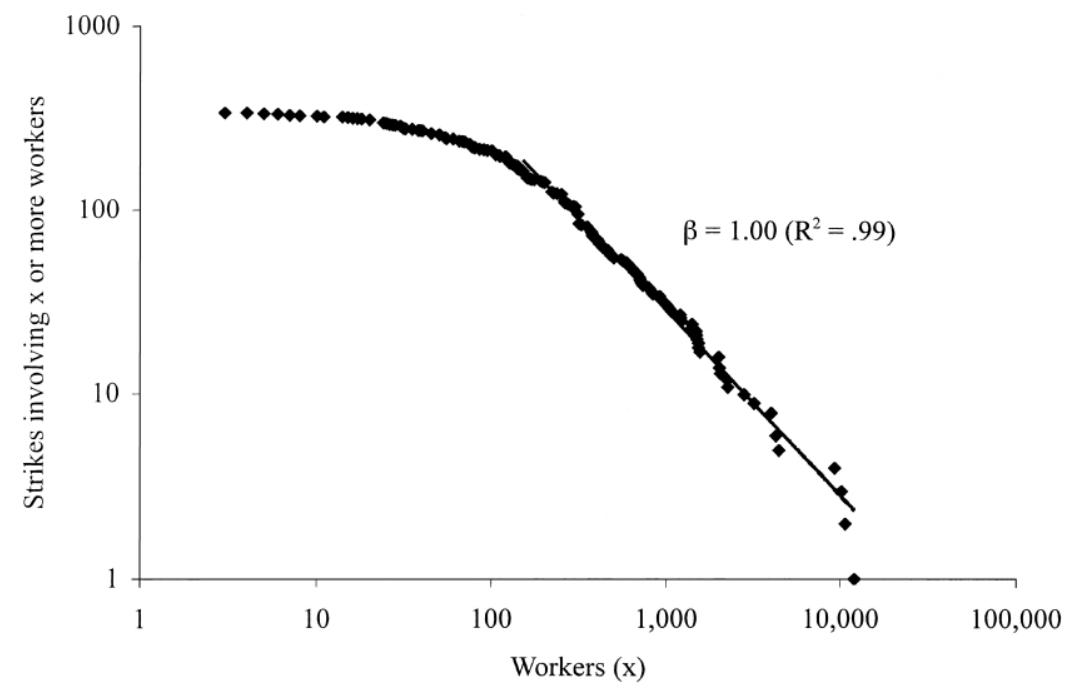

FIG. 2.-Workers involved in strikes, Chicago, 1881-86

same location, on this day-is about .53. If we see a strike wave in progress, the probability of it growing to involve twice as many firms-on this or subsequent days-is .59. Viewed incrementally, a strike or strike wave gathers momentum as it grows: it is more likely to propagate to yet one more firm. Consider the probability of a strike spreading further to involve at least another firm. For a strike in one firm the probability is .53 ; once the strike has encompassed 10 firms, it is .92; once it has encompassed 100 firms, it is .99 . Some readers may find this counterintuitive. It is easily forgotten that the conjunction of a series of high probabilities is a lower probability. Thus the probability of a strike involving at least 300 firms is only .005. A power law has no limits, but in reality strikes and strike waves-like natural events-have an upper bound. Presumably the strike wave in early May 1886 approaches the practical maximum for a city of this size.

In sum, then, we find that strikes in Chicago in the 1880s resemble natural events like wildfires, landslides, and epidemics. Cumulative distributions of event size follow a power law over two or three orders of magnitude, whether events are defined as strikes or as strike waves, and whether size is measured by the number of firms or of workers involved. This pattern encompasses numerous tiny strikes, confined to a single firm, and one extraordinary strike wave, which paralyzed the city's commerce for days. The latter now appears as an extreme event, but not an outlier. 
Strikes as Forest Fires

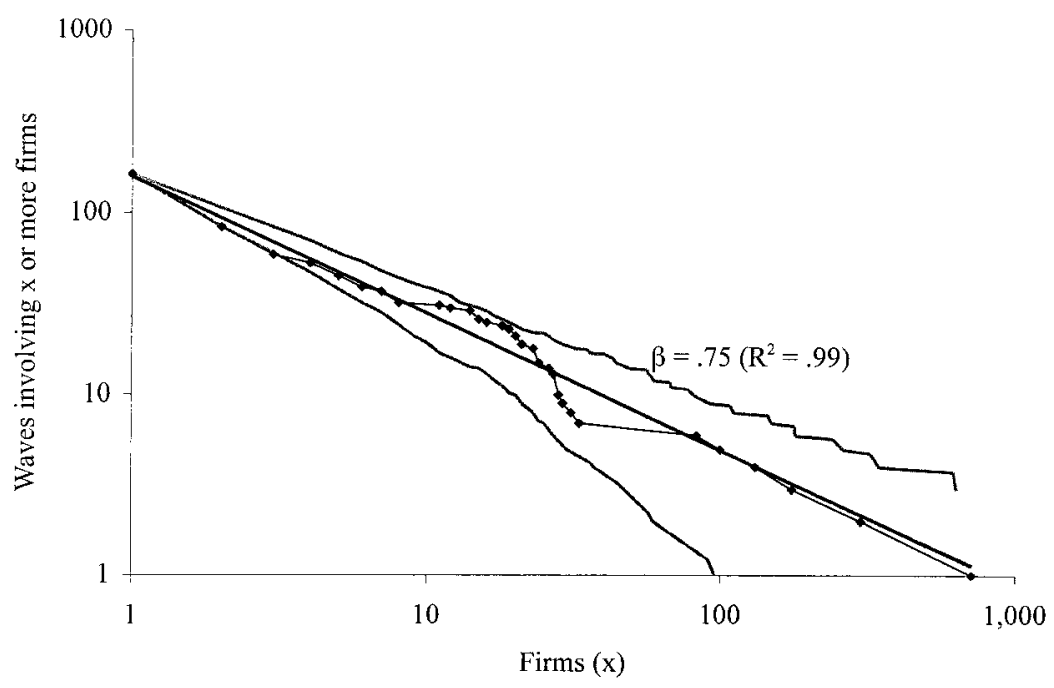

FIG. 3.-Firms involved in strike waves, Chicago, 1881-86

\section{EXTENSIONS}

It is worth applying the same method to strikes in a different national context. Patterns of class conflict differed considerably in France, as Friedman (1998) demonstrates, and so it provides a useful comparison. The French Office du Travail (subsequently Direction du Travail), inspired by the U.S. commissioner of labor, published information on strikes and lockouts from 1890 onward (available in digital format thanks to Tilly and Jordan [1984]). ${ }^{12}$ The city selected for analysis is Paris (more precisely the Seine department). It was much larger than Chicago, growing slowly from 2.5 million in 1891 (Mitchell 1975, table B4, p. 78). By comparison, Chicago doubled in size from half a million over the 1880s. The years from 1890 to 1899 yield a comparable number of strikes, 469. This period includes one significant peak of class conflict: a series of strikes by construction and allied workers in the fall of 1898, which threatened to become a general strike. Overall, however, Parisians were 10 times less likely to strike than the inhabitants of Chicago.

Table 2 summarizes the results. One caveat is in order. For 16 strikes, the number of firms (establishments, to be precise) was not recorded; several were large strikes, involving thousands of workers. ${ }^{13}$ The lacunae

${ }^{12}$ The date of strikes, excluded from Tilly and Jordan's (1984) dataset, is taken from the original reports (France-Office du Travail 1890-98; Direction du Travail 1899).

${ }^{13}$ The number of workers was modestly correlated with the number of firms (both measures logged, $r=.50$ ). 
American Journal of Sociology

TABLE 2

Size Distribution of Events: Strikes in Paris, 1890-99

\begin{tabular}{clccccc}
\hline \hline Event & Measure & Range & Threshold & $\beta$ & SE & $R^{2}$ \\
\hline Strikes $(n=469) \ldots \ldots \ldots$ & Firms $^{\mathrm{a}}$ & $1-600$ & 2 & .62 & .08 & .98 \\
& Workers & $2-14,500$ & 100 & .85 & .08 & .99 \\
Strike waves $(n=364) \ldots$ & Workers & $2-14,503$ & 100 & .83 & .09 & .99 \\
\hline a $n=453$ due to missing data & & & & & &
\end{tabular}

${ }^{\text {a }} n=453$ due to missing data.

emphasize the exceptional quality of the data collected in the United States. Figure 4 shows the cumulative distribution of firms involved in strikes. (The gray line superimposes a power law with the same slope as in figure 1.) Again, it conforms to a power law, with $\beta=.62\left(R^{2}=.98\right)-$ but only for strikes involving two or more firms. Far more strikes are confined to a single firm than would be predicted from the remainder of the distribution. In Paris, only $15 \%$ of strikes involved two or more firms, whereas in Chicago the figure was $38 \%$. Nevertheless, once Parisian workers had propagated the strike beyond a single firm, it was more likely to spread to others. The probability of a strike (once it had reached at least two firms) doubling in size is .65, compared to .53 for Chicago. The power law spans over two orders of magnitude. The cumulative distribution of workers involved in strikes (not shown) reveals a familiar pattern. A power law with $\beta=.85\left(R^{2}=.99\right)$ applies above a threshold of approximately 100 workers. The threshold is lower than in Chicago, because workplaces were smaller. (The mean number of strikes per struck firm was only 68, compared to 162, averaging across strikes.) Again, the power law spans at least two orders of magnitude.

Aggregating strikes into strike waves-as defined above-reveals minimal clustering. About four-fifths of these waves comprise a single strike, and the largest barely exceeds the largest strike. Therefore the cumulative distribution of workers involved in strike waves is essentially the same as for strikes. ${ }^{14}$ By this definition, then, there was little inspiration among different groups of workers. The definition does not capture the connections among seven successive waves in September and October 1898, which belonged to an escalating struggle on the city's building sites, swollen by preparations for the Exposition of 1900 (France-Office du Travail 1898, pp. 252-63). Over a period of a month, various groups of construction workers went out on strike, though they did not act on consecutive days. This omission alerts us to a limitation of this definition of wave.

${ }^{14}$ Missing data make it impossible to examine the number of firms involved in strike waves, because these lacunae are concentrated in the largest strike waves. 
Strikes as Forest Fires

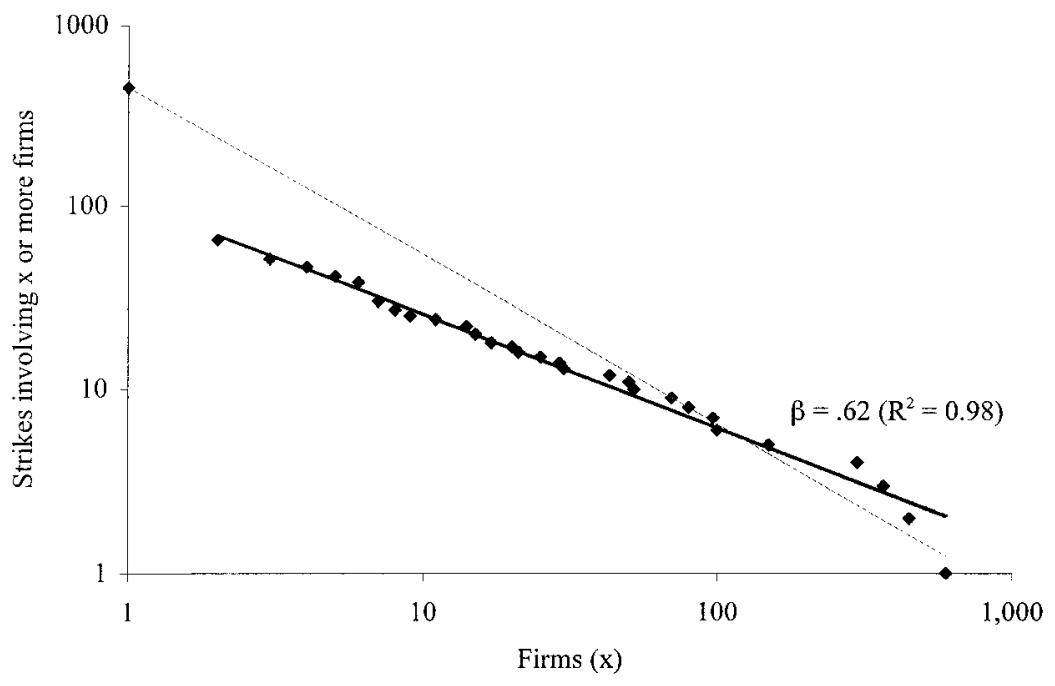

FIG. 4.-Firms involved in strikes, Paris, 1890-99

Adding all seven waves together, however, does not greatly alter the result. $^{15}$

The comparison of Chicago and Paris demonstrates some significant differences. In Paris, the analysis of strike waves does not reveal a higher level of clustering. In addition, strikes were far more likely to be confined to a single firm, and so the power law holds only for strikes involving two or more firms. These differences defy stereotypes of revolutionary France and exceptional United States. In fact, Chicago was a city at the leading edge of capitalism, with concentrations of huge establishmentsrailroad depots and meat-packing plants, for instance-while Paris retained more traditional, artisanal production. This distinction is seen in the fact that Chicago's workers were far more likely to go out on strike. Given the differences, it is remarkable that the size distribution of strikes in both cities follows a power law.

\section{DISCUSSION}

The findings provide an impressive confirmation of the intuition of historically minded observers. Just like wildfires, landslides, and epidemics,

${ }^{15}$ Adding all the strikes from September 12 to October 15, 1898, yields 42,983 workersstill far fewer than the strike wave in Chicago at the beginning of May 1886. A power law with $\beta=.90\left(\mathrm{SE}=.13, R^{2}=.97\right)$ holds for 100 workers and above. 


\section{American Journal of Sociology}

these strikes follow a power law. What are the implications of these findings? Readers familiar with population ecology (Kingsland 1995) may be reminded of an earlier debate about the implications of the logistic curve, used to describe an entity growing over time, such as national population. "An empirical formula is not so much the solution of a problem as the challenge to such solution," as Lotka observed in this context (quoted in Kingsland 1995, p. 85). A power-law distribution of events is also, in his phrase, "an animated question mark." For answers, I suggest we focus on the dynamics of collective protest; after all, social historians and historical sociologists employed those metaphors to convey their understanding of dynamics.

An alternative hypothesis, however, is worth considering first. For strikes, the power law could merely reflect the clustering of economic activity. If the number of firms (or workers) by economic sector follows a power law, and if each strike tends to involve all the local firms in one particular product or labor market, then the number of firms (or workers) involved in strikes would naturally follow a power law. This hypothesis can be tested for Chicago, as the tenement and factory inspector classified the city's establishments into 247 "trades and occupations," from agricultural implements to toys and fancy goods (Chicago Department of Health 1885, pp. 87-92). The number of firms and of workers by economic sector both conform to a lognormal distribution $\left(R^{2}=.99\right)$. The hypothesis therefore can be rejected. Moreover, it is not applicable to strike waves, because they are not confined to a particular economic sector.

To understand the dynamics of natural events like wildfires, scientists have investigated simple models that generate a power law. One family of models is characterized by "slow driving or energy input (e.g., dropping of sand grains, increase of strain, growing of trees) and rare dissipation events which are instantaneous on the time scale of driving (e.g., avalanches, earthquakes, fires)" (Drossel 1996, p. 936). ${ }^{16}$ These models, I argue, are usefully borrowed by social scientists, for they enable us to formalize the insight of historically minded observers - which, after all, has just been empirically vindicated. Such borrowing is anticipated in Hobsbawm's (1952, p. 139) discussion of strike waves: "The normal process of industrial development tends to produce explosive situations, i.e., accumulations of inflammable material which only ignite periodically." $\mathrm{He}$ wondered "whether we should regard the whole process on the . . . analogy of the ordinary internal combustion engine, whose explosion is ignited by an outside spark, or the more elegant Diesel engine, in which the

\footnotetext{
${ }^{16}$ These models have been popularized under the conceptual umbrella of "self-organized criticality" (Bak 1996). This overarching concept is less useful for social scientists, in my judgment, than particular models (Frigg [2003] provides a judicious evaluation).
} 
compression itself produces the explosion" (p. 140). Also worth noting is Hexter's (1971, chap. 5) borrowing in defense of traditional narrative history. Arguing that the French Revolution of 1789 should be explained as a process of rapid, endogenous change-rather than the inevitable effect of exogenous causes-he elaborates an analogy with the self-excited torsional oscillation that destroyed the Tacoma Narrows Bridge in 1940.

The forest fire model is offered in this spirit. It was formulated by Drossel and Schwabl (1992) after Bak, Chen, and Tang (1990; see also Clar, Drossel, and Schwabl 1996; Drossel 1996; Turcotte et al. 2002). It is a stochastic cellular automation: a two-dimensional (or $n$-dimensional) grid of cells, where the state of a cell can be affected by the state of adjacent ones. A cell is either empty, planted with a tree, or occupied by a burning tree. Flammable material gradually accumulates, as trees are randomly planted. Occasionally lightning strikes, igniting a fire which spreads across contiguous trees. More formally, on every iteration each empty cell has a certain probability, $g$, of growing a tree. There is a small probability, $s$, that a spark falls randomly on the grid. If it falls on a tree, then a fire begins. A burning tree sets alight every tree in the four neighboring cells, and the fire continues until it reaches empty cells; once burned, the cells become empty once again. Figure 5 illustrates a simulation using a $100 \times 100$ grid. ${ }^{17}$ On this iteration a fire has burned three trees on the right. The large clearing is the legacy of an earlier fire.

The cumulative size distribution of fires (measured by the number of trees burned) follows a power law. This result is robust to different specifications, so long as there are two time separations: burning is far more rapid than planting ( $g$ is sufficiently small), and planting occurs far more often than ignition ( $s / g$ is sufficiently small). If $g=.0004$ and $s=.001$, for instance, the distribution of sizes follows a power law with $\beta=.13$. The model can be altered so that a fire spreads from one tree to another with a certain probability, $f$. The cumulative distribution still follows a power law, though only when $f$ is high $(>.7)$. The model does not, however, reproduce the magnitude of $\beta(\approx .6)$ that is found with real wildfires; it generates a greater preponderance of larger fires relative to smaller ones. Needless to say, the model is not intended to represent the complexities of real wildfires. It treats the rate of accumulation $(g)$ and ignition $(s)$ as constant, whereas in reality they depend on exogenous causes like rainfall and temperature, not to mention human reactions. The point of the model is to illustrate a process of positive feedback that generates events conforming to a power law.

In this sense, the forest fire model provides a useful way of thinking

${ }^{17}$ This was implemented using RePast (http://repast.sourceforge.net/). The grid is a torus so that fires may spread from one side to the other. 


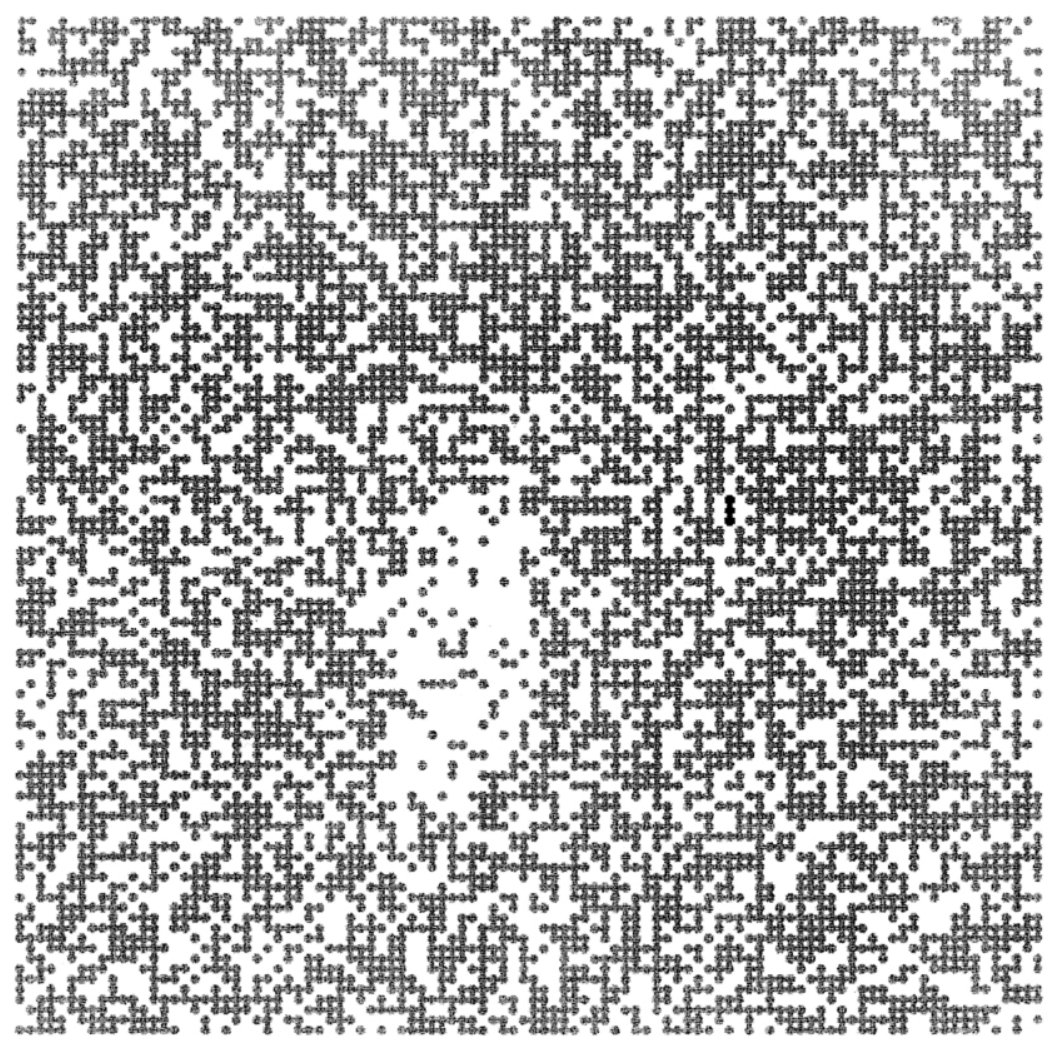

FIG. 5.-Forest fire model-example

about the dynamics of collective protest. It can be compared to the threshold model (Granovetter 1978; Granovetter and Soong 1983). Both models have the virtue of simplicity. In the threshold model, the analogous event is the number of individuals who shift from nonparticipation to participation when the distribution of thresholds is perturbed. The generative process in the threshold model follows from individual heterogeneity rather than spatial distribution, and it is deterministic rather than stochastic. The forest fire model offers two advantages. It generates a continuing series of events without changing the basic parameters. More important, the model has an empirical implication (one hesitates to say "prediction"): the cumulative distribution of event sizes should follow a power law. As we have seen, a power law can indeed be found in strikes and strike waves, albeit with a larger magnitude of $\beta$.

Needless to say, the forest fire model is not the only one to generate this kind of distribution of event sizes. Watts (2002) formulates a more 
complex model, which combines heterogeneous individual thresholds with random spatial networks. As long as connectivity is sufficiently low, this yields events (or "cascades") which follow a power law with $\beta=.5$. The utility of the forest fire model is that it explicates-in a simple mannerthe intuition of historically minded observers.

\section{CONCLUSION}

Why is transgressive contention clustered in waves? When such waves cannot be explained by changes in exogenous variables-and quantitative analyses of strikes reveal a very substantial "residual"-then we must seek an alternative type of explanation. This article contributes in three ways: conceptually, theoretically, and empirically.

Conceptually, the notion of fractals sensitizes us to the similarity of waves on different scales. A single incident of protest may result from the same kind of process as a massive "cycle of contention." At all these scales, I argue, there is evidence of positive feedback: people participate in defiant collective action (in part) because others have recently done so. Theoretically, the underlying mechanisms of interdependence and inspiration explain why previous actions by others are so influential, without resorting to irrational contagion. The forest fire model enhances our comprehension of positive feedback. As a very simple model, it is intended neither to capture the full complexity of transgressive contention nor to advance the art of modeling. Its virtue is that it is readily understood. Most important, it embodies the intuition of social historians and historical sociologists, who have persistently likened waves of collective protest to wildfires, along with avalanches and epidemics. These natural phenomena are characterized by a power-law distribution of event sizes, a characteristic replicated by the forest fire model.

Empirically, power laws have been discovered in data from two cities in the late 19th century. In Chicago from 1881 to 1886 and in Paris in the 1890s, the size distribution of strikes follows a power law spanning two or three orders of magnitude. A simple relationship encompasses the numerous small strikes, too trivial to warrant the attention of contemporaries or historians, and a few huge ones. In Chicago, moreover, the same kind of relation holds for strike waves, constituted by clusters of strikes that began on successive days; this encompasses the enormous strike wave of May 1886. To be sure, the fit is not perfect. When size is measured by the number of firms, departures at the lower end of the distribution reveal that it was relatively difficult for a strike to spread beyond a single firm. When size is measured by the number of workers, the systematic flattening of the lower portion of the distribution is ex- 
American Journal of Sociology

plained first by the tendency for a strike to involve a firm's entire workforce, and second by the paucity of strikes in smaller firms. It is the propagation of a strike among firms that gives rise to a power law; the number of workers is a derivative measure. A power law means that the probability of an (unfinished) event doubling in size remains constant, regardless of how large it has already become. Considered incrementally, the greater the number of firms already involved in a strike, the more likely it is to propagate to one more firm. This implies positive feedback.

In the course of my argument, a historical metaphor led to a novel prediction. This prediction was indeed borne out. The social historians and historical sociologists who likened strikes to wildfires, avalanches, and epidemics never expected a quantitative resemblance. Nevertheless, this empirical finding does not necessarily prove that these events were generated by an endogenous process of positive feedback, illustrated by the forest fire model. There could be alternative explanations. Hypothetically, the distribution of firms involved in strikes (though not strike waves) could merely reflect the distribution of firms within industries, supposing that strikes tend to spread to all firms in a given industry. This explanation can be rejected using data from Chicago. Other explanations-which do not posit an endogenous process of positive feedback-may be conceivable. There is, however, considerable qualitative evidence for mechanisms of interdependence and inspiration underlying workers' collective action (e.g., Biggs 2003; Fantasia 1988; Lane and Roberts 1971). At the very least, this line of investigation has discovered a hitherto unknown characteristic of strikes and strike waves. Until now, wars were the only events in the social sciences known to follow a power law.

There is no reason to believe that this empirical regularity is peculiar to Chicago and Paris in the late 19th century. Whether strikes and strike waves in other times and places follow a power law demands further investigation. We might not expect this power law to hold once collective bargaining becomes institutionalized, to the extent that strikes are decided by the ballots of union members rather than generated by the propagation of collective action. If so, then a power law could be treated as a signature of "spontaneity." Whether other kinds of collective protest follow power laws also awaits investigation. All this requires is reliable measures of the size of events. One could analyze the number of people involved in riots, for example; waves of riots across cities could be analyzed by aggregating the number of participants in riots that erupted on consecutive days.

There are implications for formal modeling too. The forest fire model generates events whose size follows a power law, but $\beta$ is considerably lower than is found for strikes and strike waves (and indeed real wildfires). One challenge is to find the minimal modification to the model which generates a similar $\beta$-in other words, generates fewer large events. Pre- 
sumably this entails replacing the grid of cells with a sparse network of connections among cells. It should be possible to discover how different types of networks generate different distributions of event size (cf. Watts 2002). Another, more ambitious, challenge is to build an agent-based model of transgressive contention that generates events that follow a power law (Macy and Willer 2002). This means abandoning the simplicity of the forest fire model in favor of a model incorporating a plausible representation of individual decision making. Such complex formal models usually escape empirical testing (Oliver 1993). The findings presented here provide a "stylized fact" for models to replicate. If the size of protest events-generated by the propagation of collective action rather than ordered by formal organizations-typically follows a power law, then formal models should also generate this kind of distribution. In a similar fashion, economists develop agent-based models of financial markets to replicate the fact that daily returns follow a power law (e.g., Lux and Marchesi 1999). Once again, this may not prove that the model is a good representation of the underlying process. Perhaps the same distribution can be generated by completely different models, though this remains to be seen. As a necessary though insufficient condition, the distribution promises guidance for constructing better models.

My argument has transgressed the boundary between social science and natural science, and between metaphors and measurement. I hope, perhaps, to have shown that these are not irreconcilable. Here, at least, scientific models converge with historical intuition. The same process can generate small events as well as huge ones. Most fires soon peter out, while a few develop into huge conflagrations. This does not reduce the significance of historical explanation, tracing how and why a particular event unfolded as it did. To explain the strike wave of May 1886 in this sense, one must understand (among other things) the unique events that brought a handful of unionists, meeting 18 months before, to resolve to enforce an eight-hour day on May 1. Yet contingency does not preclude the emergence of patterns at a higher level of abstraction. The number of firms involved in the strike wave of May 1886 in Chicago fits neatly into a power law for strike waves over several years. What may be illusory is the quest to discover the exogenous causes of huge events, to identify independent variables that predict their occurrence in space and time.

\section{APPENDIX}

Standard Errors and Prediction Intervals

Natural scientists are nonchalant about assessing how well a power law fits the data; they rely on visual inspection, supplemented by $R^{2}$. 


\section{American Journal of Sociology}

To estimate standard errors for the parameter $\beta$, I use bootstrap sampling. A sample (of size $n$ ) is drawn from the data, sampling with replacement; a power-law curve is then estimated from the resulting cumulative distribution. This procedure is repeated 1,000 times, thus providing estimates of the standard errors.

To estimate $95 \%$ prediction intervals for samples drawn from a power law, I use Monte Carlo simulation. A sample of $n$ events is drawn from the cumulative distribution described by the (estimated) power law: size $=\operatorname{round}\left(r^{-1 / \beta}\right)$ where $r$ is a random number from a uniform distribution between zero and one, and the function $\operatorname{round}(\cdot)$ rounds down to the nearest integer. This yields a cumulative distribution of event sizes, $N($ size $\geq x)$. The procedure is repeated 250 times. For each value of $x$, the 2.5 th and 97.5 th percentile are calculated. More concretely, to estimate the prediction intervals in figure 1, 341 "strikes" are created, each of size round $\left(r^{-1 / .92}\right)$. This is repeated 250 times. Then the resulting distributions are compared. Looking at the number of strikes of size $\geq 2$, for instance, the 2.5th percentile is 162 and the 97.5 th percentile is 199 . Under the hypothesis that the empirical data are actually drawn from such a distribution, we would predict (with $95 \%$ confidence) that between 162 and 199 strikes would involve two or more firms.

\section{REFERENCES}

Abbott, Andrew. 1988. "Transcending General Linear Reality." Sociological Theory 6: 169-86.

2001. Chaos of Disciplines. Chicago: University of Chicago Press.

Abbott, Andrew, and Alexandra Hrycak. 1990. "Measuring Resemblance in Sequence Data: An Optimal Matching Analysis of Musicians' Careers." American Journal of Sociology 96:144-85.

Allen, Ruth A. 1942. The Great Southwest Strike. Austin: University of Texas.

Andrews, Kenneth, and Michael Biggs. 2002. "The Dynamics of Protest Diffusion: The 1960 Sit-in Movement in the American South." Paper presented at the annual meeting of the American Sociological Association, Chicago, August.

Axtell, Robert L. 2001. "Zipf Distribution of U.S. Firm Sizes.” Science 293:1818-20.

Bak, Per. 1996. How Nature Works: The Science of Self-Organized Criticality. New York: Copernicus.

Bak, Per, Kan Chen, and Chao Tang. 1990. "A Forest-Fire Model and Some Thoughts on Turbulence." Physics Letters A 147:297-300.

Biggs, Michael. 2002. "Strikes as Sequences of Interaction: The American Strike Wave of 1886." Social Science History 26:583-617.

- 2003. "Positive Feedback in Collective Mobilization: The American Strike Wave of 1886." Theory and Society 32:217-54.

Blumer, Herbert. 1951. "Collective Behavior." Pp. 167-224 in Principles of Sociology, edited by Alfred McClung Lee. New York: Barnes and Noble.

Boulding, Kenneth E. 1968. "Business and Economic Systems." Pp. 101-17 in Positive Feedback: A General Systems Approach to Positive/Negative Feedback and Mutual Causality, edited by John H. Milsum. New York: Pergamon.

Card, David, and Craig A. Olson. 1995. "Bargaining Power, Strike Durations, and 
Strikes as Forest Fires

Wage Outcomes: An Analysis of Strikes in the 1880s." Journal of Labor Economics 13:32-61.

Cederman, Lars-Erik. 2003. "Modeling the Size of Wars: From Billiard Balls to Sandpiles." American Political Science Review 97:135-50.

Champernowne, D. G., and F. A. Cowell. 1998. Economic Inequality and Income Distribution. Cambridge: Cambridge University Press.

Chicago Department of Health. 1885. Report of the Department of Health, City of Chicago for the Year 1885. Chicago: Chicago Department of Health.

Chong, Dennis. 1991. Collective Action and the Civil Rights Movement. Chicago: University of Chicago Press.

Cioffi-Revilla, Claudio, ed. Manuscript. "Power Laws in the Social Sciences." George Mason University, Center for Social Complexity.

Clar, Siegfried, Barbara Drossel, and Franz Schwabl. 1996. "Forest Fires and Other Examples of Self-Organized Criticality." Journal of Physics: Condensed Matter 8: 6803-24.

Conell, Carol. 1988. "The Local Roots of Solidarity: Organization and Action in LateNineteenth-Century Massachusetts." Theory and Society 17:365-402.

Conell, Carol, and Samuel Cohn. 1995. "Learning from Other People's Actions: Environmental Variation and Diffusion in French Coal Mining Strikes, 1890-1935." American Journal of Sociology 101:366-403.

Conell, Carol, and Kim Voss. 1990. "Formal Organization and the Fate of Social Movements: Craft Association and Class Alliance in the Knights of Labor." American Sociological Review 55:255-69.

Currie, Janet, and Joseph Ferrie. 2000. "The Law and Labor Strife in the United States, 1881-1894." Journal of Economic History 60:42-66.

Drossel, Barbara. 1996. "Self-Organized Criticality and Synchronization in a ForestFire Model." Physical Review Letters 76:936-39.

Drossel, Barbara, and Franz Schwabl. 1992. "Self-Organized Critical Forest-Fire Model.” Physical Review Letters 69:1629-32.

Edwards, P. K. 1981. Strikes in the United States, 1881-1974. New York: St Martin's. Elster, Jon. 1989. Nuts and Bolts for the Social Sciences. Cambridge: Cambridge University Press.

Engels, Friedrich. 1887. Preface to The Condition of the Working Class in England in 1844, translated by Florence Kelley Wischnewetzky. New York: John W. Lovell.

Fantasia, Rick. 1988. Cultures of Solidarity: Consciousness, Action, and Contemporary American Workers. Berkeley and Los Angeles: University of California Press.

Federation of Organized Trades and Labor Unions of the United States and Canada. 1884. Report of the Fourth Annual Session of the Federation of Organized Trades and Labor Unions of the United States and Canada held in Chicago, Illinois, October 7, 8, 9, and 10, 1884. Imprint.

France-Direction du Travail. 1899. Statistique des grèves et des recours à la conciliation et à l'arbitrage survenus pendant l'annee 1899. Paris: Imprimerie Nationale.

France-Office du Travail. 1891-98. Statistique des grèves. Paris: Imprimerie Nationale.

Franzosi, Roberto. 1995. The Puzzle of Strikes: Class and State Strategies in Postwar Italy. Cambridge: Cambridge University Press.

Frette, Vidar, Kim Christensen, Anders Malthe-Sørenssen, Jens Feder, Torstein Jøssang, and Paul Meakin. 1996. "Avalanche Dynamics in a Pile of Rice." Nature 379:49-52.

Friedman, Gerald. 1988. "Strike Success and Union Ideology: The United States and France, 1880-1914." Journal of Economic History 48:1-25.

. 1998. State-Making and Labor Movements: France and the United States, 1876-1914. Ithaca, N.Y.: Cornell University Press. 


\section{American Journal of Sociology}

1999. "New Estimates of Union Membership: The United States, 1880-1914." Historical Methods 32:75-86.

Frigg, Roman. 2003. "Self-Organised Criticality-What It Is and What It Isn't." Studies in History and Philosophy of Science 20:613-32.

Fujita, Masahisa, Paul Krugman, and Anthony J. Venables. 1999. The Spatial Economy: Cities, Regions, and International Trade. Cambridge, Mass.: MIT Press.

Granovetter, Mark. 1978. "Threshold Models of Collective Behavior." American Journal of Sociology 83:1420-43.

Granovetter, Mark, and Roland Soong. 1983. "Threshold Models of Diffusion and Collective Behavior." Journal of Mathematical Sociology 9:165-79.

Griffin, Larry J. 1993. "Narrative, Event-Structure Analysis, and Causal Interpretation in Historical Sociology." American Journal of Sociology 98:1094-1133.

Hedström, Peter. 1994. "Contagious Collectivities: On the Spatial Diffusion of Swedish Trade Unions, 1890-1949." American Journal of Sociology 99:1157-79.

_ 1998. "Rational Imitation." Pp. 306-27 in Social Mechanisms: An Analytical Approach to Social Theory, edited by Peter Hedström and Richard Swedberg. Cambridge: Cambridge University Press.

Hedström, Peter, Rickard Sandell, and Carlotta Stern. 2000. "Mesolevel Networks and the Diffusion of Social Movements: The Case of the Swedish Social Democratic Party." American Journal of Sociology 106:145-72.

Hexter, J. H. 1971. The History Primer. New York: Basic Books.

Hobsbawm, Eric J. 1952. "Economic Fluctuations and Some Social Movements since 1800." Pp. 126-57 in Labouring Men: Studies in the History of Labour. London: Weidenfeld and Nicolson.

- 1985. "The 'New Unionism' Reconsidered." Pp. 13-31 in The Development of Trade Unionism in Great Britain and Germany, 1880-1914, edited by Wolfgang J. Mommsen and Hans-Gerhard Husung. London: George Allen and Unwin.

Kaufman, Bruce E. 1982. "The Determinants of Strikes in the United States, 1900-1977." Industrial and Labor Relations Review 35:473-90.

Kingsland, Sharon E. 1995. Modeling Nature: Episodes in the History of Population Ecology, 2d ed. Chicago: University of Chicago Press.

Koopmans, Ruud. 2004. "Protest in Time and Space: The Evolution of Waves of Contention." Pp. 19-46 in The Blackwell Companion to Social Movements, edited by David A. Snow, Sarah A. Soule, and Hanspeter Kriesi. Malden, Mass.: Blackwell.

Kuran, Timur. 1991. "Now Out of Never: The Element of Surprise in the East European Revolution of 1989." World Politics 44:7-48.

- 1995. Private Truths, Public Lies: The Social Consequences of Preference Falsification. Cambridge, Mass.: Harvard University Press.

Kurzman, Charles. 1996. "Structural Opportunity and Perceived Opportunity in SocialMovement Theory: The Iranian Revolution of 1979." American Sociological Review 61:153-70.

Lane, Tony, and Kenneth Roberts. 1971. Strike at Pilkington's. London: Collins/ Fontana.

Liljeros, Frederik. 2001. "The Complexity of Social Organizing." Ph.D. dissertation. Stockholm University, Department of Sociology.

Lux, Thomas, and Michele Marchesi. 1999. "Scaling and Criticality in a Stochastic Multi-Agent Model of a Financial Market.” Nature 397:498-500.

Macy, Michael W., and Robert Willer. 2002. "From Factors to Actors: Computational Sociology and Agent-Based Modeling." Annual Review of Sociology 28:143-66.

Malamud, Bruce D., and Donald L. Turcotte. 1999. "Self-Organized Criticality Applied to Natural Hazards." Natural Hazards 20:93-116.

Mandelbrot, Benoit B. 1963. "The Variation of Certain Speculative Prices." Journal of Business 36:394-419.

-1983. The Fractal Geometry of Nature. New York: W. H. Freeman. 
Strikes as Forest Fires

McAdam, Doug, Sidney Tarrow, and Charles Tilly. 2001. Dynamics of Contention. Cambridge: Cambridge University Press.

McCammon, Holly J. 1993. "From Repressive Intervention to Integrative Prevention: The U.S. State's Legal Management of Labor Militancy, 1881-1978." Social Forces 71:569-602.

Mitchell, B. R. 1975. European Historical Statistics, 1750-1970. New York: Columbia University Press.

Moore, Barrington. 1978. Injustice: The Social Bases of Obedience and Revolt. White Plains, N.Y.: M. E. Sharpe.

Myers, Daniel J. 1997. "Racial Rioting in the 1960s: An Event History Analysis of Local Conditions." American Sociological Review 62:94-112.

. 2000. "The Diffusion of Collective Violence: Infectiousness, Susceptibility, and Mass Media Networks.” American Journal of Sociology 106:173-208.

Oberschall, Anthony. 1989. "The 1960s Sit-ins: Protest Diffusion and Movement TakeOff." Research in Social Movements, Conflict, and Change 11:31-53.

Oliver, Pamela E. 1989. "Bringing the Crowd Back In: The Nonorganizational Elements of Social Movements." Research in Social Movements, Conflict, and Change 11:1-30.

_. 1993. "Formal Models of Collective Action." Annual Review of Sociology 19: 271-300.

Oliver, Pamela E., and Daniel J. Myers. 2003. "The Coevolution of Social Movements." Mobilization 8:1-24.

Olson, Mancur. 1971. The Logic of Collective Action: Public Goods and the Theory of Groups, 2d ed. Cambridge, Mass.:Harvard University Press.

Pelletier, Jon D., Bruce D. Malamud, Troy Blodgett, and Donald L. Turcotte. 1997. "Scale-Invariance of Soil Moisture Variability and Its Implications for the Frequency-Size Distribution of Earthquakes." Engineering Geology 48:255-68.

Perrot, Michelle. (1984) 1987. Workers on Strike: France, 1871-1890. Leamington Spa: Berg.

Persky, Joseph. 1992. "Pareto's Law.” Journal of Economic Perspectives 6:181-92.

Pigou, A. C. 1929. Industrial Fluctuations, 2d ed. London: Macmillan.

Polletta, Francesca. 1998. "'It Was Like a Fever . . .' Narrative and Identity in Social Protest." Social Problems 45:137-59.

Rhodes, C. J., and R. M. Anderson. 1996. "Power Laws Governing Epidemics in Isolated Populations." Nature 381:600-602.

Richardson, Lewis F. 1948. "Variation of the Frequency of Fatal Quarrels with Magnitude." Journal of the American Statistical Association 43:523-46.

Roberts, D. C., and D. L. Turcotte. 1998. "Fractality and Self-Organized Criticality of Wars." Fractals 6 (2): 351-57.

Rosenbloom, Joshua L. 1998. "Strikebreaking and the Labor Market in the United States, 1881-1894." Journal of Economic History 58:183-205.

Schelling, Thomas C. 1978. Micromotives and Macrobehavior. New York: Norton.

Schneirov, Richard. 1998. Labor and Urban Politics: Class Conflict and the Origins of Modern Liberalism in Chicago, 1864-97. Urbana and Chicago: University of Illinois Press.

Shorter, Edward, and Charles Tilly. 1974. Strikes in France, 1830-1968. Cambridge: Cambridge University Press.

Skeels, Jack W. 1982. "The Economic and Organizational Basis of Early United States Strikes, 1900-1948." Industrial and Labor Relations Review 35:491-503.

Snyder, David. 1975. "Institutional Setting and Industrial Conflict: Comparative Analyses of France, Italy and the United States." American Sociological Review 40: 259-78.

. 1977. "Early North American Strikes: A Reinterpretation." Industrial and Labor Relations Review 30:325-41. 


\section{American Journal of Sociology}

Soule, Sarah. 1997. "The Student Divestment Movement in the United States and the Shantytown: Diffusion of a Protest Tactic." Social Forces 75:855-83.

Strang, David, and Nancy Brandon Tuma. 1993. "Spatial and Temporal Heterogeneity in Diffusion." American Journal of Sociology 99:614-39.

Tarrow, Sidney. 1998. Power in Movement: Social Movements and Contentious Politics, 2d ed. Cambridge: Cambridge University Press.

Tilly, Charles, and David K. Jordan. 1984. "Strikes and Labor Activity in France, 1830-1960." Computer file no. 8421. Inter-university Consortium for Political and Social Research, Ann Arbor, Mich.

Turcotte, Donald L. 1997. Fractals and Chaos in Geology and Geophysics, 2d ed. Cambridge: Cambridge University Press.

Turcotte, Donald L., Bruce D. Malamud, Fausto Guzzetti, and Paola Reichenbach. 2002. "Self-Organization, the Cascade Model, and Natural Hazards." Proceedings of the National Academy of Sciences 99:2530-37.

U.S. Commissioner of Labor. 1887. Third Annual Report: Strikes and Lockouts. Washington, D.C.: Government Printing Office.

Voss, Kim. 1988. "Labor Organization and Class Alliance: Industries, Communities, and the Knights of Labor." Theory and Society 17:329-64.

1993. The Making of American Exceptionalism: The Knights of Labor and Class Formation in the Nineteenth Century. Ithaca, N.Y.: Cornell University Press.

Watts, Duncan J. 2002. "A Simple Model of Global Cascades on Random Networks." Proceedings of the National Academy of Sciences 99:5766-71.

Zipf, George Kingsley. 1949. Human Behavior and the Principle of Least Effort: An Introduction to Human Ecology. Cambridge, Mass.: Addison-Wesley. 